\title{
Effect of water quantity and quality on the properties of alginate impression materials
}

\section{Wpływ jakości i ilości wody na właściwości alginatowych materiałów wyciskowych}

\author{
Zbigniew Raszewski ${ }^{1, A, B, D, F}$, Agnieszka Nowakowska-Toporowska ${ }^{2, C, E, F}$, Joanna Weżgowiec ${ }^{3, C, E, F}$, Danuta Nowakowska ${ }^{2, A, D, F}$ \\ 1 Spofa Dental Kerr Company, Jičin, Czech Republik \\ 2 Department of Dental Prosthetics, Wroclaw Medical University, Poland \\ ${ }^{3}$ Department of Experimental Dentistry, Wroclaw Medical University, Poland \\ A - research concept and design; $\mathrm{B}$ - collection and/or assembly of data; $\mathrm{C}$ - data analysis and interpretation; \\ $D$ - writing the article; $E$ - critical revision of the article; $F$ - final approval of the article
}

Address for correspondence

Joanna Weżgowiec

E-mail: joanna.wezgowiec@umed.wroc.pl

Funding sources

The study was financed from statutory funds

of Wroclaw Medical University, Poland.

Conflict of interest

None declared

Received on 0ctober 5, 2017

Reviewed on November 26, 2017

Accepted on January 8, 2018

DOI

$10.17219 / \mathrm{dmp} / 82179$

Copyright

() 2018 by Wroclaw Medical University

and Polish Dental Society

This is an article distributed under the terms of the

Creative Commons Attribution Non-Commercial License

(http://creativecommons.org/licenses/by-nc-nd/4.0/)

\begin{abstract}
Background. Alginates are impression materials commonly used in prosthodontics and orthodontics. However, all these materials have some disadvantages, such as limited elasticity, tearing resistance and low dimensional stability.

Objectives. The aim of this research was to investigate the effect of various water quantities and qualities on changes in the properties of alginates.

Material and methods. Two alginates, Neocolloid and Tulip, were mixed with different volumes of water, water with calcium ions, or sparkling water with $\mathrm{CO}_{2}$. The dimensions, setting times, and hardness of the specimens were measured and Young's modulus was calculated. The significance of the difference between the mean values of different groups and the control group was assessed by Student's t-test or the Mann-Whitney U test.
\end{abstract}

Results. The dimensional stability changes of both alginate impression materials were statistically dependent on the quantity of water used for mixing. Sample storage over $24 \mathrm{~h}$ of samples prepared with $+15 \%$ water led to 5.00\% shrinkage for Neocolloid and 4.41\% for Tulip. The setting times of Neocolloid and Tulip were significantly prolonged when the alginates were prepared with $+15 \%$ water; the addition of calcium ions shortened the setting times of both alginates. Specimens mixed with the water containing $\mathrm{Ca}^{2+}$ ions were characterized by greater hardness and Young's modulus values when compared to the alginate mixed with distilled water.

Conclusions. For mixing alginates, it is necessary to use the manufacturers' recommended mixing ratios between powder and water. To obtain the right setting time, hardness and elasticity, the application of distilled or demineralized water is advised.

Key words: hardness, dental impression materials, irreversible hydrocolloids, storage conditions, dimensional changes

Słowa kluczowe: twardość, dentystyczne materiały wyciskowe, nieodwracalne hydrokoloidy, warunki przechowywania, zmiany wymiarów 


\section{Introduction}

Alginates are impression materials commonly used in prosthodontics and orthodontics for preliminary or final impressions for acrylic appliances, preparation of provisional restorations, impressions of opposite dentition, fabrication of diagnostic and orthodontic models, sports mouthguards, bleaching trays, and more. The popularity of alginates results from the satisfactory reproduction of details, ease of use, very good hydrophilicity, and low cost. However, these materials have some disadvantages, such as limited elasticity, tearing resistance, and low dimensional stability upon storage. Despite the recommendations of most of the manufacturers, in clinical practice impressions are often not poured immediately after removal from the mouth, especially when the dental surgery and dental prosthetics laboratory are not in the same place. Such procedure influences the final precision, since, over time, alginates shrink as a result of the evaporation of water from their structure (dehydration) and spontaneous syneresis. ${ }^{1-3}$ From the beginning of their use in dentistry, there have been many studies concerning a wide range of properties of alginates. Many authors have investigated the effects of different factors and conditions on the mechanical properties, dimensional accuracy and stability after storage on the basis of examinations of casts made from this type of impression material. ${ }^{4-12}$ Additionally, the influence of the mixing method (manual or automatic) and disinfection procedure on the reproduction of details, elastic recovery and tensile strength of alginates have been analyzed. ${ }^{13}$ Farzin and Panahandeh have shown that low storage temperature $\left(4^{\circ} \mathrm{C}\right)$ prolonged the dimensional stability of alginate impressions. ${ }^{14}$

Alginates, like irreversible hydrocolloids, are very sensitive to the mixing ratio between powder and water. Manufacturers add suitable spoons for powder and measuring cups for water, but it is possible to use these accessories imprecisely, i.e., due to a problem with the meniscus of water or because of using powder which has been packed or settled in the container, particularly after storage over a long period of time. In such conditions, the obtained mixing ratio may differ from the recommended one, resulting in as much as $15 \%$ excess or shortage of water. Obviously, different mixing proportions between powder and water may change the setting characteristics and the viscosity of alginate impression materials. ${ }^{15}$

Additionally, not only the quantity, but also the quality of water has an impact on the properties of alginates. There are studies describing the influence of gypsum on the setting time of alginates. Calcium sulfate dehydrate is present in the powder of alginate impression material to enable cross-linking of alginic chains. However, in excess it may accelerate the setting process. ${ }^{16}$ Moreover, despite the fact that alginate manufacturers strongly recommend distilled water without other ions, which could influence the setting time, tap water is frequently used in common dental practice. Due to a possibly high concentration of different ions, using tap water may also increase or decrease the setting time of alginates.

\section{Objectives}

The aim of this study was to investigate the effect of various quantities and qualities of water on dimensional changes during storage, as well as changes of setting time, hardness and elastic modulus of alginate impression materials.

\section{Material and methods}

\section{Material}

Two commercial alginates were used: Tulip ${ }^{\circledR}$ (Cavex, Haarlem, Holland) - a chromatic material, which changes its color during the mixing process, and Neocolloid ${ }^{\circledR}$ (Zhermack, Badia Palesine, Italy) without a color indicator. Tulip is an example of alginate with a lower mixing ratio between powder and water $(17 \mathrm{~g} / 39 \mathrm{~mL})$ compared to Neocolloid (19.5 g/39 mL). Neocolloid is used for precise impressions. Powders and water were measured using a laboratory balance KPZ 2-05-3 (KPZ, Czech Republic).

\section{Sample preparation}

In total, 7 groups of samples (5 groups prepared with different quantities of water, 1 group with water with gypsum and 1 group with water with a higher concentration of carbon dioxide) were prepared for Tulip and Neocolloid alginates. For each experimental group, 3 samples were prepared and tested. In the first part of the experiment, the samples of $9 \mathrm{~g}$ of powder (Tulip or Neocolloid) were mixed with distilled water with $10 \%$ and $15 \%$ less water and $10 \%$ and $15 \%$ more water, respectively, than recommended by the manufacturer. However, preparation of the alginates with a $15 \%$ shortage of water was not possible because of a lack of sufficient volume of water to mix it properly with powder. For this reason, only the setting time of the sample prepared with $15 \%$ less water was measured, and the measurements of the other parameters (dimensional changes and Shore A hardness) were not performed. In the next part, the samples of both the alginates with the same weight, were mixed with water with calcium ions. Water saturated with calcium sulfate was obtained by immersion of $10 \mathrm{~g}$ of calcium sulfate dehydrate (Sigma-Aldrich, St. Louis, USA) in $200 \mathrm{~mL}$ of distilled water, and storage of this solution for $24 \mathrm{~h}$ in $100 \%$ humidity at the laboratory temperature. This kind of water saturated with calcium sulfate can reflect the situation of using the same bowl for mixing gypsum and alginate without a thorough washing. In the last part, the alginate samples were mixed with sparkling water Żywiec (Żywiec Zdrój Corp., Żywiec, Poland) saturated with $600 \mu \mathrm{g} / \mathrm{dm}^{3}$ of $\mathrm{CO}_{2}$, as an example of tap water quality occurring in some geographical regions.

The alginates were mixed manually in a rubber bowl for $45 \mathrm{~s}$. The temperature of the powder and the water 
was $23^{\circ} \mathrm{C}$. Metal molds were used to form rectangular samples with dimensions of $10 \mathrm{~mm} \times 60 \mathrm{~mm} \times 3 \mathrm{~mm}$. To obtain the samples, the metal molds were placed on a glass plate. After that, open spaces in the molds were filled with the mixed alginate and then covered with a second glass plate. After the alginate was set, the glass covers were removed and the samples were removed carefully. All the samples were stored in polyethylene (PE) string bags with a wet cotton ball inside to maintain $100 \%$ humidity for the whole testing period and protect the samples from additional drying. For each group, 3 samples were prepared.

\section{Dimensional changes}

An optical microscope at a magnification of $\times 20$ (Delta Optical Genetic, Mińsk Mazowiecki, Poland) was used to measure dimensional changes of the samples. Two metal pins (Renfert, Hilzingen, Germany) were inserted into the alginate samples at a distance of $5 \mathrm{~mm}$ from the ends of the sample on each side (Fig. 1$)$. The distance $( \pm 0.01 \mathrm{~mm})$ between the pins in the sample was measured after $30 \mathrm{~min}$ and $1,2,3,4,5,6$, and 24 h of storage of the alginates after the setting time. The first measurement was conducted after 30 min to allow the material to come back to its original dimensions after being removed from the metal form. This time interval was used to simulate clinical conditions with the time needed in dental practice for the recovery of the impression material after being removed from the patient's oral cavity.

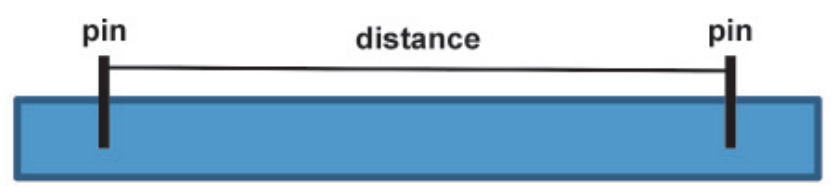

Fig. 1. Measurement of distance between 2 pins inside the alginate sample for evaluating dimensional changes of the sample upon storage

\section{Setting time}

The cone \& plate CAP 2000+ viscometer (Brookfield Engineering Laboratories, Middleboro, USA) was used to determine the setting times of the alginate materials. This instrument subjected the sample to an oscillating stress of constant amplitude and frequency and it measured the resulting oscillating strain profile. All procedures were made under standardized conditions at room temperature. Before starting the experiment, the incubator was set to $23^{\circ} \mathrm{C}$ and allowed to stabilize. After $30 \mathrm{~s}$ of mixing the powder with water, the material was loaded between the cones of the viscometer and the time was measured till the material set completely. The same procedure was adapted for the alginates mixed with gypsum and sparkling water. For determination of setting time, 3 samples were used for each group. The setting time was defined as the length of time taken for obtaining $40 \%$ reduction in chart width plus $30 \mathrm{~s}$ for the mixing process.

\section{Shore hardness}

Metal molds with a diameter of $50 \mathrm{~mm}$ and thickness of $6 \mathrm{~mm}$ were placed on to a glass slab, filled with the alginate and covered by the second slab. After $15 \mathrm{~min}$, the alginate discs were carefully removed. Shore A Hardness Durometer (Sauter GmbH, Balingen, Germany) was used to determine the hardness of the samples loaded with $10 \mathrm{~N}$ for a period of $15 \mathrm{~min} .{ }^{13}$

\section{Calculation of Young's modulus}

Young's modulus of the tested samples was calculated using Gent's equation, which determines the relationship between Shore hardness (s) and Young's modulus (E) for alginates: 6 measurements for each sample at each time point were performed and the mean value was calculated. ${ }^{17}$

\section{Statistical analysis}

The results were expressed as a mean value of 3 measurements for each sample. The same materials prepared with mixing ratios recommended by the manufacturer, with distilled water, were used as the control sample. The data was analyzed with the use of STATISTICA v. 12 (StatSoft Inc., Tulsa, USA) software. The significance of the difference between mean values of different groups and the control group was assessed using Student's t-test (for data distributed normally), with $\mathrm{p}$-value of $\mathrm{p} \leq 0.05$ or $\mathrm{p} \leq 0.005$, or the Mann-Whitney $U$ test (for data not distributed normally) with $\mathrm{p}$-value of $\mathrm{p} \leq 0.05$, to show the statistical significance.

\section{Results}

\section{Effect of water quantity on dimensional changes}

The results of the experiments showing the effect of water quantity on dimensional changes of the samples during storage are shown in Fig. 2 for Tulip and Fig. 3 for Neocolloid. The statistically significant differences between the dimensional changes of the tested samples prepared with $-10 \%$, $+10 \%$ and $+15 \%$ water and the control sample prepared with the recommended mixing ratios were observed for both the alginates at most of the time points. The dimensional changes observed for samples prepared with the water excess $(+10 \%$ or $+15 \%)$ were larger than with lack of water (-10\%) both for Tulip and Neocolloid. After 24 h of storage, the Tulip samples prepared with $+15 \%$ water shrank by $-4.41 \% \pm 0.02 \%$ (for the control $-1.57 \% \pm 0.03 \%$ ) and Neocolloid samples changed dimensions by $-5.00 \% \pm 0.02$ (for the control $-1.57 \% \pm 0.01 \%$ ). 


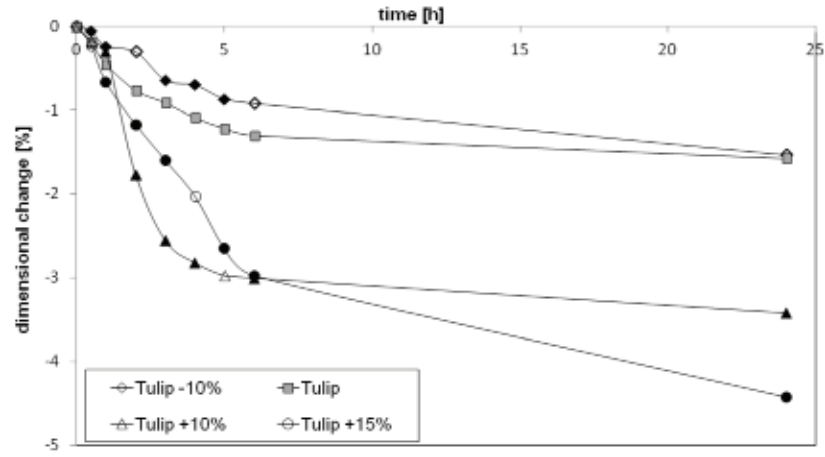

Fig. 2. Dimensional changes during storage of Tulip mixed with different volumes of water; grey color of markers denotes the control group for each time point, black color denotes differences significant at the 0.005 level, white color denotes differences not significant at the 0.05 level

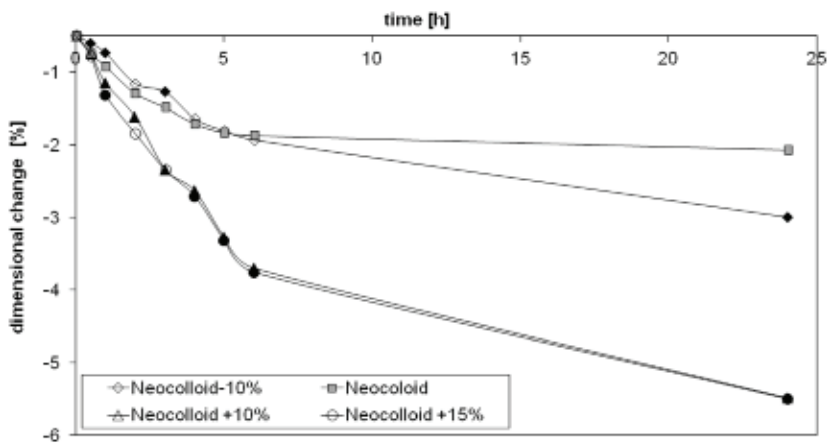

Fig. 3. Dimensional changes during storage of Neocolloid mixed with different volumes of water; grey color of markers denotes the control group for each time point, black color denotes differences significant at the 0.005 level, white color denotes differences not significant at the 0.05 level

\section{Effect of water quality on dimensional changes}

Both alginate impression materials mixed with non-distilled water in mixing ratios recommended by the manufacturer had different properties upon storage. The results of these tests are presented in Fig. 4 (for water with a higher concentration of calcium sulfate) and Fig. 5 (for acidic water with a higher concentration of carbon dioxide).

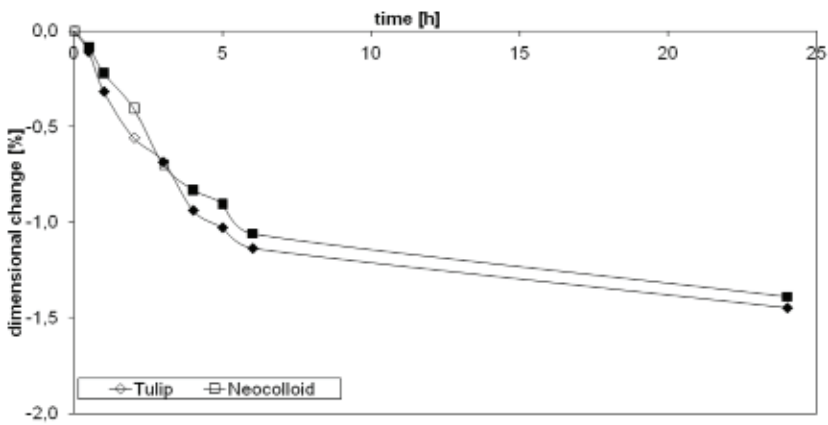

Fig. 4. Dimensional changes during storage of the alginates mixed with water with calcium sulfate; data related to the control group (the alginates mixed with the recommended volume of water, without calcium sulfate), black color of markers denotes differences significant at the 0.005 level, white color denotes differences not significant at the 0.05 level

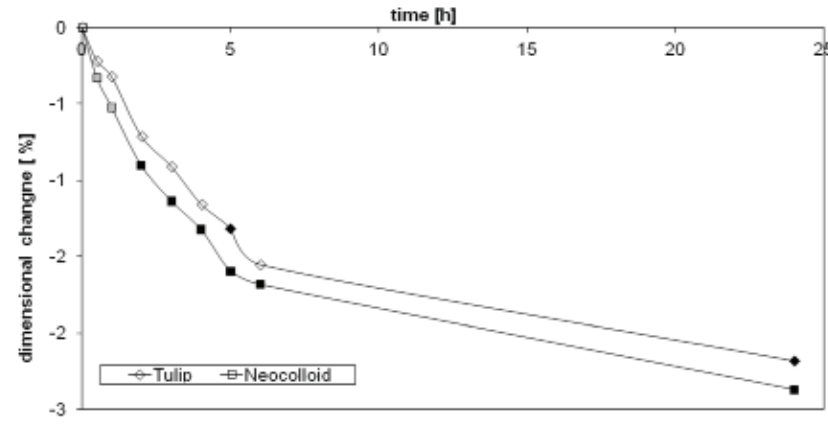

Fig. 5. Dimensional changes during storage of the alginates mixed with water with carbon dioxide; data related to the control group (the alginates mixed with the recommended volume of water, without carbon dioxide), black color of markers denotes differences significant at the 0.005 level, grey color denotes differences significant at the 0.05 level, white color denotes differences not significant at the 0.05 level

After $24 \mathrm{~h}$, for Tulip mixed with water with a higher concentration of calcium sulfate a contraction of $-1.45 \%$ was observed and for Neocolloid it was $-1.39 \%$ (Fig. 4). For the same materials mixed with water with higher contractions of carbon dioxide, the contraction was $-2.18 \%$ for Tulip and $-2.37 \%$ for Neocolloid (Fig. 5).

\section{Setting time}

The results of the measurements of setting time for both the alginate impression materials are presented in Fig 6. Preparation of alginates with a mixing ratio different than the ratio recommended by the manufacturers also had an impact on the measured setting time of both materials. A prolonged setting time was observed with the water excess, while water loss resulted in a reduced setting time. The most significant differences were observed when both alginates were prepared with $+15 \%$ water.

The presence of calcium ions from calcium sulfate shortened the setting time of both materials most significantly - for Tulip $81 \mathrm{~s}$ as compared to $153 \mathrm{~s}$ for the control prepared with the manufacturer's recommended mixing ratio. A similar reduction of the setting time was observed

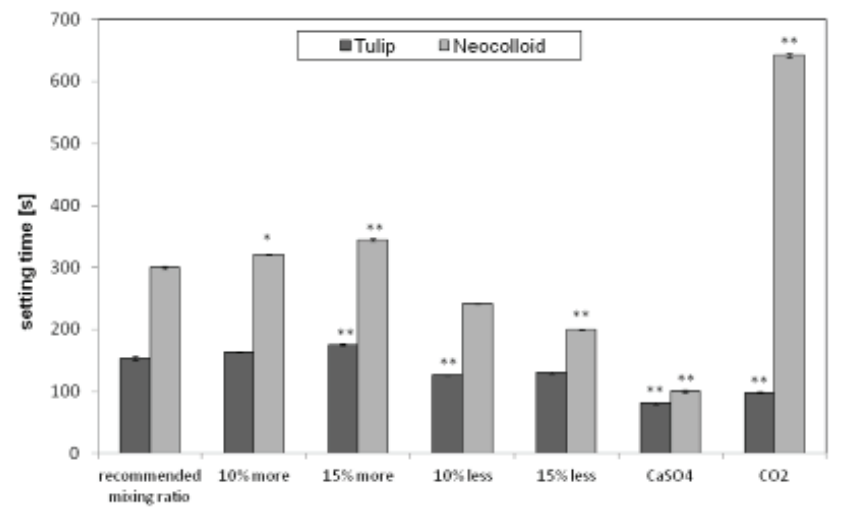

Fig. 6. Changes in setting time of Tulip and Neocolloid; data related to the control group (the alginates prepared with the recommended mixing ratios $p \leq 0.05 ;{ }^{* *} p \leq 0.005$ ) 
for Neocolloid (101 s as compared to $300 \mathrm{~s}$ for the control). The use of sparkling water caused significant prolongation of the setting time from $300 \mathrm{~s} \pm 3 \mathrm{~s}$ to $642 \mathrm{~s} \pm 3 \mathrm{~s}$ for Neocolloid material, while for Tulip, the setting time was reduced from $153 \mathrm{~s} \pm 3 \mathrm{~s}$ to $99 \mathrm{~s} \pm 2 \mathrm{~s}$. For both materials the observed differences were statistically significant.

\section{Hardness and Young's modulus}

The results of the Shore A hardness measured $15 \mathrm{~min}$ after mixing and Young's modulus of both the alginate impression materials are presented in Table 1 . The measured decrease of hardness and elasticity was related to the water excess. Samples mixed with water containing gypsum ions were characterized by increased hardness (32 Shore A for Neocolloid and 23 Shore A for Tulip). The same relationship was observed for Young's modulus - 0.78 MPa for Neocolloid and 0.44 MPa for Tulip, in relation to the alginates mixed with the recommended mixing ratios: $0.54 \mathrm{MPa}$ and $0.40 \mathrm{MPa}$, respectively.

\section{Discussion}

Alginate materials, as gel forms, contain more than $60 \%$ of water in their structures. During storage, water can evaporate and this process is responsible for the shrinkage of alginate impressions. ${ }^{1,2}$ The impact of water quantity and quality on the setting time and mechanical properties of alginate impression materials have not been sufficiently clarified in previous studies. ${ }^{4-16}$ In the present research, it was shown that the quantity of water had a significant influence on the setting process and viscoelastic behavior of both impression materials. Changing the recommended mixing ratios between powder and water caused changes of the setting time, Shore A hardness and Young's modulus. Additionally, the quality of water used for mixing with alginate powder is crucial for obtaining impressions of adequate quality. If water contains calcium ions, the setting time was reduced. This experiment revealed a reduced setting time from $300 \pm 2 \mathrm{~s}$ to $102 \pm 3 \mathrm{~s}$ for Neocolloid and from $153 \pm 2 \mathrm{~s}$ to $81 \pm 3 \mathrm{~s}$ for Tulip. This effect can be explained because of the fact that ions from the second group of the periodic table can easily react with sodium alginate to form a gel. Calcium sulfate dehydrate is even added to the formulation of alginate powder (usually as $7-10 \%$ of the total weight) to cross-link the alginate. However, if more is added, the reaction may be disturbed, which should be avoided. For this reason, in dental practice it is necessary to use separate bowls, one for mixing alginate and the second for mixing gypsum products, to prevent the contamination between calcium ions and salt of alginic acid, i.e., sodium or potassium alginate, which is present in the alginate powder. In the presence of water, the monovalent ions $\left(\mathrm{Na}^{+}\right.$or $\left.\mathrm{K}^{+}\right)$are replaced by divalent calcium ions, which crosslink the alginate.

The changes of setting time in the group where sparkling water was used for mixing were statistically significant for both the alginates, but for Tulip the setting time was shortened, and for Neocolloid it was prolonged. The significant prolongation of the setting time of Neocolloid may be explained by the fact that sparkling water contains $\mathrm{CO}_{2}$. Being a week acid, it can form salts with ions, worsen their solubility in water and increase the setting time of Neocolloid. Therefore, from the clinical point of view, the use of water containing $\mathrm{CO}_{2}$ in the mixing procedure of alginates is not recommended. However, according to information from patents (US patent 2008/0057465 A1 and US patent 6,559,200 B1) and Buchan \& Peggie publications, some producers have used magnesium oxide for preparing alginates, since it can easily react with $\mathrm{CO}_{2}$ and neutralize it. ${ }^{18-20}$ Quantity and quality of water also had an effect on the hardness and elastic modulus of the alginates. Increasing the water quantity resulted in a decrease of the material hardness and its elastic modulus. This may be related to the effect of water as a plasticizer. An excess of $\mathrm{Ca}(2+)$ can cross-link alginic chains more effectively and, as a result, the final hardness and elastic modulus could increase while the setting time could be reduced.

\section{Conclusions}

The results of the present study suggest that for mixing alginate impression materials, it is necessary to use the manufacturers' recommended mixing ratio between pow-

Table 1. Hardness and Young's modulus of Neocolloid and Tulip prepared using different mixing procedures); data related to the control group (the alginates prepared with the recommended mixing ratios)

\begin{tabular}{|c|c|c|c|c|}
\hline \multirow{2}{*}{ Group } & \multicolumn{2}{|c|}{ Neocolloid } & \multicolumn{2}{|c|}{ Tulip } \\
\hline & hardness [Shore A] & Young's modulus [MPa] & hardness [Shore A] & Young's modulus [MPa] \\
\hline Recommended mixing ratio & $25.6 \pm 0.5$ & $0.53 \pm 0.02$ & $21.8 \pm 0.4$ & $0.40 \pm 0.01$ \\
\hline$-10 \%$ water less & $28.4 \pm 0.5^{* *}$ & $0.63 \pm 0.02^{* *}$ & $26.0^{* *}$ & $0.54^{* *}$ \\
\hline$+10 \%$ water excess & $21.8 \pm 0.4^{* *}$ & $0.40 \pm 0.01^{* *}$ & $19.8 \pm 0.8^{* *}$ & $0.33 \pm 0.03^{* *}$ \\
\hline$+15 \%$ water excess & $20.0 \pm 0.7^{* *}$ & $0.34 \pm 0.02^{* *}$ & $18.2 \pm 0.8^{* *}$ & $0.28 \pm 0.02^{* *}$ \\
\hline Water with calcium ions & $31.8 \pm 0.4^{* *}$ & $0.77 \pm 0.02^{* *}$ & $22.8 \pm 0.4^{*}$ & $0.43 \pm 0.01^{*}$ \\
\hline Water with carbon dioxide & $24.8 \pm 0.8^{*}$ & $0.50 \pm 0.03^{*}$ & $22.0 \pm 0.7$ & $0.40 \pm 0.02$ \\
\hline
\end{tabular}

${ }^{*} \mathrm{p} \leq 0.05 ;{ }^{* *} \mathrm{p} \leq 0.005$. 
der and water. An excess of water increases changes of the alginate mass dimensions and reduces hardness and elasticity of these materials. A shortage of water causes the opposite effects. Moreover, to get the right setting time, hardness and elasticity of the final impression, the use of distilled or demineralized water is advised. The addition of water rich in calcium ions improves the mechanical parameters of the studied alginates but also accelerates their binding.

\section{References}

1. King $S$, See $H$, Thomas $G$, Swain M. Determining the complex modulus of alginate irreversible hydrocolloid dental material. Dent Mater. 2008;24:1545-1548.

2. Fellows CM, Thomas GA. Determination of bound and unbound water in dental alginate irreversible hydrocolloid by nuclear magnetic resonance spectroscopy. Dent Mater. 2009;25:486-493.

3. Ercoli C, Abrahamsen TC. A simple method for making accurate duplicate casts. J Prosthet Dent. 1996;76:457.

4. Brown D. Factors affecting the dimensional stability of elastic impression materials. J Dent. 1973;1:265-274.

5. Sedda M, Casarotto A, Raustia A, Borracchini A. Effect of storage time on the accuracy of casts made from different irreversible hydrocolloids. J Contemp Dent Pract. 2008;9:59-66.

6. Walker MP, Burckhard J, Mitts DA, Williams KB. Dimensional change over time of extended-storage alginate impression materials. Angle Orthod. 2010;80:1110-1115.

7. Nassar U, Hussein B, Oko A, Carey JP, Flores-Mir C. Dimensional accuracy of 2 irreversible hydrocolloid alternative impression materials with immediate and delayed pouring. J Can Dent Assoc. 2012;78:c2.

8. Nallamuthu NA, Braden M, Patel MP. Some aspects of the formulation of alginate dental impression materials-setting characteristics and mechanical properties. Dent Mater. 2012;28:756-762.

9. Rohanian A, Ommati Shabestari G, Zeighami S, Samadi MJ, Shamshiri AR. Effect of storage time of extended-pour and conventional alginate impressions on dimensional accuracy of casts. J Dent (Tehran). 2014;11:655-664.

10. Frank RP, Thielke SM, Johnson GH. The influence of tray type and other variables on the palatal depth of casts made from irreversible hydrocolloid impressions. J Prosthet Dent. 2002;87:15-22.

11. Kulkarni MM, Thombare RU. Dimensional changes of alginate dental impression materials - An in vitro study. J Clin Diagn Res. 2015;9:ZC98-ZC102.

12. Guiraldo RD, Moreti AF, Martinelli J, et al. Influence of alginate impression materials and storage time on surface detail reproduction and dimensional accuracy of stone models. Acta Odontol Latinoam. 2015;28:156-161.

13. Dreesen K, Kellens A, Wevers M, Thilakarathne PJ, Willems G. The influence of mixing methods and disinfectant on the physical properties of alginate impression materials. Eur J Orthod. 2013;35:381-387.

14. Farzin M, Panahandeh $\mathrm{H}$. Effect of pouring time and storage temperature on dimensional stability of casts made from irreversible hydrocolloid. J Dent (Tehran). 2010;7:179-184.

15. Wanis TM, Combe EC, Grant AA. Measurement of the viscosity of irreversible hydrocolloids. J Oral Rehabil. 1993;20:379-384.

16. Powers JM, Sakaguchi RL. Impression materials. In: Restorative Dental Materials. $12^{\text {th }}$ ed. St. Louis: Mosby; 2006;272-279.

17. Gent AN. Indentation hardness and Young's modulus. Transactions of the Institute of Rubber Industry. 1958;34:47-57.

18. GC Corp (2008). Dental alginate impression material composition. US20080057465A1.

19. GC Corp (2003). Dental alginate impression material composition. US patent 6,559,200 B1.

20. Buchan S, Peggie RW. Role of ingredients in alginate impression compounds. J Dent Res. 1966;45:231-236. 